\title{
Sobre el compromiso político del arte (y los artistas) en Pobre gente de París de Sebastián Salazar Bondy
}

\author{
On the political commitment of art (and artists) in Pobre gente de París by \\ Sebastián Salazar Bondy \\ Américo Mudarra Montoya \\ Universidad Nacional Mayor de San Marcos \\ Contacto:amudarram@unmsm.edu.pe
}

\begin{abstract}
Resumen
Desde nuestra perspectiva, el texto Pobre gente de París es un manifiesto poético-político. En él, nuestro autor intenta coincidir la visión del escritor literario y la visión del activista político.

El libro no es, pues, un mero conjunto de "vivencias parisinas" emparentadas por su condición de "material autobiográfico" sino, más bien, un vehículo de ideas, el cual continuará por la misma ruta que venían formando sus artículos de opinión en la prensa escrita de aquellos años.

Entonces, logramos observar que las ideas de Salazar Bondy discurren sin dificultad entre las líneas del texto Pobre gente de París. La condena dictada en la página de algún periódico aparece nuevamente en las páginas de este libro, quizá con otras palabras, quizá con diferente extensión, pero siempre con la misma indignación, con la misma ira.

Palabras clave: Narrativa peruana, manifiesto poético-político, Sebastián Salazar Bondy.
\end{abstract}

\begin{abstract}
From our perspective, the text Pobre gente de París is a poetic-political manifesto. In it, our author tries to agree on the vision of the literary writer and the vision of the political activist.

The book is not, therefore, a mere set of "Parisian experiences" related by its condition of "autobiographical material". Rather, it is a vehicle of ideas, which will continue along the same route that had formed their articles of opinion in the written press of those years.

Then, we can observe that the ideas of Salazar Bondy run without difficulty between the lines of the text Pobre gente de París. The condemnation dictated in the page of a newspaper appears again in the pages of this book, perhaps in other words, perhaps with different extension, but always with the same indignation, with the same anger Keywords: Peruvian narrative, poetic-political manifesto, Sebastián
\end{abstract}


Salazar Bondy

Recibido: 15.01 .17

Aceptado: 13.02 .17

\section{Sebastián Salazar Bondy: ¿“persona oscura”?}

Desde la perspectiva de la crítica literaria peruana, hasta hace unos años atrás, la obra de Sebastián Salazar Bondy (Lima, 1924-1965), escritor, periodista e intelectual de los sesenta, se hallaba reducida a un único libro: Lima la horrible, publicado en 1964. Un conjunto de ensayos donde arremetía contra la principal estrategia de la oligarquía criolla para hacer prevalecer su supremacía: la fanática exaltación del pasado, sea a través del arte o de la política. Operación que Salazar Bondy bautizó como el mito de la "arcadia colonial”. Sin embargo, su producción en otros géneros fue dejada de lado. Inclusive, las puestas en escena de algunas de sus piezas teatrales — con las que había logrado hasta en dos oportunidades el Premio Nacional de Teatro-, se volvieron apenas aventuras anecdóticas. Sus libros de poesía, muy celebrados en su momento, solo podían ubicarse en los anaqueles de ciertas bibliotecas o en los rincones más inhóspitos de las populares librerías de viejo. Y en las aulas universitarias, la percepción era la misma. Salazar Bondy, pese a haber sido uno de los más activos representantes de la denominada Generación del 50' — prueba de ello es que junto con Jorge Eduardo Eielson y Javier Sologuren editó la antología La poesía contemporánea del Perú (1946) — y pese, también, a haber sido el animador cultural más importante de su época, se había convertido verdaderamente en esa "persona oscura”, por la clandestinidad en la que cayeron tanto su figura como su legado, que ya prefiguraba en el título de uno de sus primeros libros.

Una clara evidencia de lo que aquí mencionamos nos la ofrece el crítico Luis Rebaza, en el artículo con el que inicia su libro La construcción del artista peruano contemporáneo, donde, sobre Salazar Bondy declara:

En lo personal, quisiera decir que entre las muchas sorpresas que me deparó la confección de este volumen estuvo el acceso a un perfil más completo de la figura de Sebastián Salazar Bondy. Si bien su papel como crítico e ideólogo de la segunda mitad de este siglo en el Perú es claro para los miembros de su generación, y está todavía presente 
entre ellos, yace ignorado por las generaciones posteriores. (Rebaza, 2000, p. 23; el énfasis es nuestro)

Así, inevitablemente, nos debemos hacer una primera interrogante: ¿por qué sobrevino este progresivo desvanecimiento de la figura de Sebastián Salazar Bondy cuando puede decirse que él llegó a ser para la Generación del 50' su adalid, su rostro más público, debido a su participación en la política2 y el periodismo3? Basta con que revisemos las declaraciones que se fueron generando alrededor del hombre y de la obra para demostrar que su valoración no fue exagerada. No solo de parte de quienes lo acompañaron en distintas empresas culturales, como los poetas Emilio Adolfo Westphalen o Javier Sologuren, sino también de aquellos que tuvieron la oportunidad de tratar con él, como el novelista Mario Vargas Llosa.

Comencemos con las palabras de Emilio Adolfo Westphalen, quien, junto con José María Arguedas — como bien lo ha señalado Luis Rebaza en su trabajo ya referido-, llegó a ser uno de los principales guías de todo ese grupo, tanto por su influencia literaria como por su magisterio en otras áreas4. Westphalen, en un ensayo dedicado a la poesía de Salazar Bondy, consciente de que no contaba aún con el distanciamiento debido como para poder expresarse de forma totalmente objetiva, sin verse afectado por los recuerdos y las emociones que ellos suelen provocar, no opta por el comentario crítico; lo hace, más bien, por el de realizar un esbozo de lo que él consideraba habían sido los rasgos más esenciales del amigo ausente. Motivado por aquel impulso señala contundentemente que:

[...] la poesía no fue en Sebastián ocupación marginal, inconsciente o mudable, sino meollo, corazón, núcleo vital de su ser. Es ella la que permitió el equilibrio de su vida, por ella no cedió al vértigo de la desesperación, en ella se redime de todo trajín inútil, de tanto trabajo vano por remover la fealdad y maldad que nos apabulla. La poesía es su triunfo secreto. (Westphalen 2004, pp. 462-463)

Para el autor de Las ínsulas extrañas, la poesía se le ofrece a Salazar Bondy 
como una fuente inagotable de sentido, verdad y coherencia, que alimentará a todas sus demás actividades. De modo que una lectura estricta de su poesía -y creemos que es posible extenderlo a sus demás producciones- contribuiría a develar la auténtica naturaleza de su pulsión creadora.

Javier Sologuren, amigo íntimo desde la etapa universitaria en San Marcos de Salazar Bondy, también lleva a cabo una revisión general de su poesía, tratando de identificar el proceso evolutivo que en ella se da. Cumpliendo, él sí, con el debido distanciamiento temporal del que abjuraba Westphalen, ya que este ensayo aparecerá publicado a diez años de la muerte del compañero polígrafo. Será muy importante tener en cuenta la conclusión a la que llegue. Pues más allá de las cualidades particulares que consigue resaltar, lo será por el hecho de que nos reafirmará el valor de Salazar Bondy dentro de otros géneros:

En la perspectiva de la Generación del 50', la obra de Sebastián Salazar Bondy (constituida, además, por su teatro, ensayo y narrativa) ha seguido, como se podrá fácilmente advertir, un sendero de paulatina socialización, situándose de ese modo en la vertiente vallejiana de nuestra poesía, con autenticidad, y fino y penetrante acento personal. (Sologuren 1988, p. 283; el énfasis es nuestro)

En tan solo una breve línea, se nos revela la clasificación que, originalmente, se hizo de la obra de Salazar Bondy. Sologuren no hace más que señalar las expectativas e intereses por parte de la escena literaria local para con el legado de nuestro autor. Por ende, no resulta casual que, mientras se lee e interpreta la obra poética, los otros géneros sean nombrados como parte de un solo conglomerado; de allí, también, el uso de paréntesis, lo que demuestra su pertenencia —según esta visión— a un segundo orden. Por otro lado, tampoco es algo meramente fortuito que Sologuren distribuya de la siguiente manera aquellos otros géneros: "teatro, ensayo y narrativa", ya que se ajustaba convenientemente con la realidad. El teatro de Salazar Bondy ya había sido reconocido5. Respecto a su ensayística, tanto sus artículos periodísticos y sus críticas de arte como la publicación de Lima la horrible habían hecho de él, como hoy se diría, un influyente líder de opinión, con alcance no solo en los circuitos 
artísticos, sino también en ámbitos de los más diversos.

Mario Vargas Llosa, por el primer aniversario de la partida de Sebastián Salazar Bondy, también colabora en la misma publicación —hablamos del número doble (7-8) de la Revista Peruana de Cultura (1966)— donde también sale impreso originalmente el ensayo de Westphalen que revisamos previamente. Logrando una mezcla de testimonio con comentario crítico sobre Salazar Bondy, Vargas Llosa redacta uno de sus ensayos más emblemáticos. Y es que en él se nos descubrirá aparte del talentoso narrador, también al hábil polemista ${ }^{6}$ que, amparado en los principios ideológicos que en aquella época defendía, pretende alborotar la escena literaria local. Desde la figura de Sebastián Salazar Bondy como paradigma, Vargas Llosa proyecta en el tiempo lo que deben ser la constitución y la actitud modélicas de un escritor peruano contemporáneo. Más aún, cuando este se halla situado en medio de un entorno que lo atosiga:

Durante mucho tiempo, con aliados eventuales, encarnó la vida literaria del Perú. Yo lo recuerdo muy bien porque, diez años atrás [1956] y por esta razón, su nombre y su persona resultaban fascinantes para mí. Todo, en el Perú, contradecía la vocación de escritor, en el ambiente peruano ella adoptaba una silueta quimérica, una existencia irreal. Pero ahí estaba ese caso extraño, ese hombre orquesta, esa demostración viviente de que, a pesar de todo, alguien lo había conseguido. ¿Quién de mi generación se atrevería a negar lo estimulante, lo decisivo que fue para nosotros el ejemplo de Sebastián? ¿Cuántos nos atrevimos a intentar a ser escritores gracias a su poderoso contagio? (Vargas Llosa 2003, p. 30-31)

Para Vargas Llosa, la literatura peruana tiene un antes y un después, ya que encuentra un hito histórico en la figura de Sebastián Salazar Bondy. En este ensayo se nos evidencia un importante proceso que se está gestando en aquellos años: las posibles barreras que podrían imponerse frente a alguien que desea seguir la carrera de escritor ya no tienen que ser las de mero índole socioeconómico. El escritor peruano, fuese cual fuese su situación dentro de la sociedad, encontrará — a partir de ese momento— las maneras, los medios, para continuar con su profesión. Muestra de ello lo será el propio Vargas Llosa quien, 
como sabemos, tuvo que desempeñarse como periodista, además de otros empleos, para perseguir su vocación.

Entonces, para obtener una respuesta a nuestra interrogante inicial, debemos reunir lo apuntado por estos tres autores. Así pues, si hacemos una lectura aguda de sus comentarios, además de tener en cuenta las principales publicaciones realizadas por y en torno a Sebastián Salazar Bondy hasta el día de hoy, advertiremos que las lecturas finalmente privilegiadas con el pasar de los años, reafirmadas también por el canon de la crítica peruana, sobre todo, tras su muerte en 1965, nos proponen la siguiente composición: la presencia de tres tendencias, donde dos de ellas se refugian en una y de ese modo atraviesan el tiempo. Como si de los afluentes de un enorme río se trataran y este desembocase en una especie de delta.

La primera tendencia, el primer momento que puede ser reconocido desde 1965 y se irá diluyendo —incorporándose irremediablemente a la segunda tendencia - hacia mediados de los setenta. La segunda tendencia, la mayor y más vigorosa, desde 1964, pero que se mantendrá vigente hasta la actualidad. Y la tercera tendencia, el tercer momento, que se manifestará inicialmente en 1990 —la formación del delta—, aunque se expandirá enérgicamente hasta inicios del año 2000.

La primera tendencia se detiene en la producción poética de Salazar Bondy. Es importante señalar el papel capital que desempeñó nuestro autor en la divulgación y el juicio críticos de la poesía peruana. No solo a través de la ya mencionada antología La poesía contemporánea del Perú de 1946, sino también con la publicación, en colaboración con Alejandro Romualdo, de Antología general de la poesía peruana (1957), y su sola selección: Mil años de poesía peruana (1963). Por ello, no debe sorprendernos que Westphalen y Sologuren, en sus respectivos textos, prefieran dar cabida a la producción poética. La segunda tendencia, el segundo momento, se formará a partir de la recepción oficial de Lima la horrible.

Si bien no es este el espacio adecuado para que examinemos sus propuestas y aportes, no debemos dejar de indicar que aquel libro se convirtió en una obra de 
gran impacto, como ha sucedido en contadas ocasiones en el Perú. Pues gracias a él es que la figura de Sebastián Salazar Bondy logra mantenerse considerada por la crítica peruana hasta la actualidad. Además, que el nombre del libro pasa a ser parte del lenguaje colectivo para expresar de manera exacta el desencanto de los propios limeños para con su ciudad. Por último, la tercera tendencia, el tercer momento, solo será posible una vez terminada la etapa más álgida del conflicto armado interno que asoló —y trastocó radicalmente-al país. Se había llegado al punto en que se hacía una total demonización de los pensadores e intelectuales que eran de izquierda, tan solo por el hecho de haber pertenecido a ella. Es en 1990, con la publicación de Una voz libre en el caos, los ensayos y artículos de crítica de arte, que se inicia una nueva revisión de la producción de Salazar Bondy. A inicios de la primera década del año 2000 crecerá el interés por esta otra faceta: el escritor de ensayos y artículos periodísticos. En 2003 sale impreso Escritos políticos y morales, recopilación de artículos publicados en diversos diarios peruanos y que fue preparada por la Universidad de San Marcos, y en 2005, el primer estudio panorámico de su obra, mas no solo como creador o pensador, sino como difusor y promotor cultural, nos referimos a Sebastián Salazar Bondy: Pasión por la cultura, del investigador francés Gerald Hirschhorn.

\section{Un nuevo acercamiento a Salazar Bondy: más allá de Lima la horrible}

Si retomamos nuestra imagen del río, ahora nos ubicamos dentro de un nuevo momento, una nueva tendencia. Este se consolida recién en los últimos años, debido precisamente a la relectura de la obra de Salazar Bondy. Concretamente, hablamos del estudio y análisis de sus piezas teatrales, así como de sus colecciones narrativas. Tarea impostergable de la crítica contemporánea, más aún, cuando caemos en cuenta que su posición dentro de la poesía y el ensayo no se encuentra en discusión. De allí que, en este trabajo, optemos por acercarnos a aquella sección de su obra que siempre fue mirada de soslayo: la narrativa. Hecho que no deja de ser llamativo, pues apenas la conforman tres títulos: los libros de cuentos Náufragos y sobrevivientes (1954) y Pobre gente de París (1958), así como la novela póstuma Alférez Arce, teniente Arce, capitán Arce (1969). 
Para comenzar a hablar de su narrativa y de la recepción que se tuvo de ella en la época, nos remitiremos a una de las muchas cartas, compiladas por Inés Westphalen, que intercambiaron José María Arguedas y Emilio Adolfo Westphalen. Hay una, escrita por el narrador andahuaylino desde su reducto de Puerto Supe, fechada el 19 de marzo de 1959, que guarda el siguiente comentario: “[...] el flaco vale cada día menos y creo que mejora como periodista. ¿Has leído su esperpento sobre París?" (Westphalen Ortiz, 2011, p. 200). Sin duda alguna sorprende el tono con que se expresan dichas palabras ${ }^{7}$. Se entiende que se está refiriendo al segundo libro de cuentos publicado por Salazar Bondy: Pobre gente de París. Pero también debe entenderse que se trata de dos de nuestros escritores más celosos para con el manejo del lenguaje y el cuidado en la creación literaria. Arguedas se atormentaba continuamente por su insuficiente capacidad para traducir al castellano, y a través de la escritura, las sensaciones producidas en su interior por la cosmovisión andina. Mientras que bastará con indicar que Westphalen se tomó cerca de cincuenta años para publicar un nuevo libro de poesía. Así que nos aventuraríamos a señalar que la orientación del comentario se halla regida por una seria preocupación estética, antes que por algún tipo de recelo o animadversión hacia la persona de Salazar Bondy. Esta actitud — la de ignorar su producción narrativa— también la observaremos en la crítica peruana, la cual prácticamente guardará silencio, salvo un par de excepciones muy puntuales, acerca de sus libros de cuentos y su novela póstuma. Aunque llegue a ser incluido dentro del grupo de narradores más importantes de la generación del 50', no dejará de ser un dato referencial, pues no se profundizará ni se analizará sus libros. Estuardo Núñez lo ubica dentro de la categoría neo-objetivista del cuento, es decir, de tendencia realista pero sin abandonar su interés por cuidar la estructura y el estilo de la narración. Mientras tanto, Antonio Cornejo Polar, en "Hipótesis sobre la narrativa peruana última" (2013 [1979]), y Miguel Gutiérrez, en Generación del 50: un mundo dividido (2008 [1988]), lo incluyen y nombran, pero no dejan comentario alguno sobre cualquiera de sus libros. Solamente Tomás Escajadillo y Mario Vargas Llosa 
intentan una revisión más exhaustiva del valor y aporte de la producción narrativa de Salazar Bondy.

Desde el punto de vista del estudioso y especialista en narrativa indigenista Tomás Escajadillo, la obra de Salazar Bondy busca ser un retrato de la clase media, de los individuos que la integran, inmersos en diferentes condiciones y enfrentados a diversas situaciones:

Nos parece necesario destacar el papel de 'pionero' que le ha cabido a Salazar Bondy — dentro de las últimas generaciones de narradores-, en cuanto al deseo de mostrar no ya simplemente la angustia existencial del hombre urbano, sino concretamente, el personaje de la clase media. (Escajadillo, 1994, pp. 185-208)

De allí que en Náufragos y sobrevivientes se le celebre la intención de explorar aquella parte de la sociedad limeña que nadie, hasta ese momento — los años cincuenta-, se ha decidido a hacerlo. Escajadillo, continuando con su lectura, agregará que respecto a Pobre gente de París la clase media continúa siendo el eje de las narraciones de Salazar Bondy, puesto que por el tipo de historias que lo conforman (artistas latinoamericanos atrapados en una existencia miserable y mediocre), no pueden ser más que representaciones de sujetos de dicho estrato social: no pertenecen a las clases altas, porque sino se encontrarían en una mejor situación económica; ni a las clases bajas, porque todos ellos, aparte de no contar con una formación académica desarrollada, no tienen la posibilidad de viajar al extranjero. Sin embargo, Escajadillo sostendrá que el objetivo perseguido por el autor (retratar la vida del hombre de clase media) no es conseguido en ninguno de estos dos libros, aunque lo trate de exaltar colocándolo como referente de los siguientes narradores:

Si este mundo —o como gusta decir Sebastián, esta 'mitología'—, de la clase media alcanza mejores realizaciones literarias en la obra de los autores más jóvenes, especialmente en la obra posterior de Julio Ramón Ribeyro y Mario Vargas Llosa, pero también en la de Zavaleta y Reynoso, creo que no debe olvidarse que fue Sebastián quien abrió la ruta, quien intentó mostrar un 'personaje' ausente, en ese momento, de la literatura nacional. Si no lo logró plenamente en sus primeros libros, estamos seguros que algo aprenderían de ellos los narradores más jóvenes, así solo haya sido el poder cotejar las limitaciones de los cuentos de Salazar Bondy, con la peculiar imagen u necesidad de expresión que ellos tenían de 'la mitología' de la clase media urbana 
(1994, p. 195; el énfasis es nuestro).

El estudioso peruano señalará al libro póstumo de Salazar Bondy, Alférez Arce, Teniente Arce, Capitán Arce —edición póstuma que, coincidentemente, estuvo a cargo del propio Escajadillo_-, como su obra narrativa de mayor valor.

En cambio, para Mario Vargas Llosa, el libro que debe ser leído y releído con mayor atención es, precisamente, Pobre gente de París. (Hay que tener en cuenta que para cuando realizó el ensayo citado, se desconocía la novela que venía preparando Salazar Bondy.). En sus palabras, este libro

[...] encierra una dura sátira contra quienes huyen espiritual y físicamente de su mundo y pretenden entregarse a otro, más sensible y adecuado a la vocación literaria o artística [...]. Cuando escribió estos relatos, Sebastián llevaba varios años empeñado a probarse a sí mismo que un escritor peruano podía ejercer su vocación sin necesidad de huir al extranjero o de parapetarse en su mundo interior. (2003, p. 29)

Resalta a primera vista que este es un Vargas Llosa joven, seguidor de ideales similares a los de Salazar Bondy, y lo que pretende al momento de escribir este ensayo — sobre todo estas últimas líneas — es rescatar la voluntad incólume del Salazar Bondy creador para mantenerse no obstante las adversidades del medio; pese, inclusive, al rechazo de que sea un literato que tuvo "más ideas políticas que otra cosa” (2003, p. 83), como el propio Salazar Bondy lo sostuviera en uno de sus artículos periodísticos. De alguna manera, el autor del ensayo, a través de la figura del protagonista de su reflexión, se protege a sí mismo de posibles críticas por el mismo asunto ${ }^{8}$. Entonces, podemos deducir, gracias al comentario del escritor arequipeño, que desde este segundo libro de Salazar Bondy nacen dos líneas temáticas bien marcadas: el rechazo hacia los artistas exiliados, condenando su escapismo y su oportunismo; y la necesidad de defender la existencia de una literatura comprometida con una ideología, en este caso con el socialismo humanista, sin que aquello significase su total sumisión.

Justamente, esta última circunstancia, el compromiso de la literatura con la ideología política, será la que más polémicas le traerá a Salazar Bondy. Y es 
que él rechazó la idea de deslindar al escritor y a los demás artistas de la política:

[Se] Plantea nuevamente el viejo tema de literatura y deber social, de literatura y vida, de literatura y conducta. Si el que esto escribe está en la política no es, por cierto, por vocación. Es por algo más obligatorio e ineludible: por deber. Ya que se trata de algo connatural a todos los hombres, sobre todo cuando viven en sociedad. (2003, p. 181)

Pero al trasladar a su creación literaria los postulados políticos que defiende, aquello le valdrá que se le reconozca como un escritor dominado por la cuestión ideológica. Probablemente, esto nos ayude a entender el comentario de Arguedas, en su carta a Westphalen, descalificando Pobre gente de París. Sin embargo, la lectura de Vargas Llosa, que acabamos de revisar y que, frente a la carta de Arguedas, fue llevada a cabo posteriormente, encuentra en ese mismo libro un material de calidad.

Es obvia la contraposición de estas dos posturas acerca de Pobre gente de París. Por un lado Arguedas, y, por el otro, Vargas Llosa. El juicio que vierte Arguedas se formula desde una perspectiva, llamémosle, más estilística, más de autor: "esperpento". Por otra parte, Vargas Llosa se pronuncia a partir de la cuestión ideológica: "un escritor peruano podía ejercer su vocación sin necesidad de huir al extranjero o de parapetarse en su mundo interior". Recordemos que el tránsito de la década de 1950 a la de 1960 está definido por un persistente debate alrededor del grado de compromiso que debe tomar la literatura para con la política. En este caso, la diferencia reside en qué tanto tendría que involucrarse la una con la otra, excluyéndose la posibilidad de reunir lo estético con lo ideológico.

Por la dirección que toma nuestra lectura tenemos que concentrarnos en la escritura practicada por Salazar Bondy en dicho título. Y es que Pobre gente de París no se ajusta al modelo típico de literatura "comprometida", es decir, de estilo naturalista, al servicio de una causa, promoviendo la ideología del proletariado universal. En los cuentos que lo conforman no descubriremos el esquema esperado del realismo socialista —que es el nombre también usado 
para describir dicha literatura—, con los seres más desvalidos, los abandonados de la vida, devorados por la injusticia, producto del capitalismo inmisericorde. Tampoco descubriremos a figuras paradigmáticas sobresaliendo de entre la masa (el proletariado, los estudiantes, los obreros, los campesinos) y dirigiendo a los sedientos de justicia hacia un nuevo orden social. Su literatura escapará de esas características. Todo ello sintonizará con la visión de socialismo que manejaba nuestro autor: no uno marxista, sino uno humanista. Con mayor interés por obtener un equilibrio dentro de la sociedad, basado en la igualdad de oportunidades, antes que por esperar a desatar una lucha de clases. Resulta preciso, entonces, escuchar la opinión que Santiago Agurto —arquitecto peruano y uno de los compañeros de Salazar Bondy en la experiencia política del Movimiento Social Progresista—, tenía del grupo: "El Movimiento Social Progresista es un socialismo no marxista, es como decir, éramos los comunistas que íbamos a misa. Buscamos un gobierno por el pueblo y para el pueblo" (Heysen, 2008, p. 201). Una marca indeleble de Salazar Bondy fue la permanente consagración de la solidaridad entre los hombres. Su lucha en pos de una esperanza, la idea de un Perú mejor y su obra, definida a partir de una severa preocupación por los otros, por los olvidados de la sociedad, nos lleva a afirmar que la vinculación de poética y política es indisoluble. Entre ambas se yergue tan solo el tiempo transparente.

Por lo que podemos atrevernos a señalar que Pobre gente de París se trata de un manifiesto poético-político. En él, nuestro autor intenta hacer coincidir la visión del escritor literario y la visión del activista político. El libro no es, pues, un mero conjunto de "vivencias parisinas" emparentadas por su condición de "material autobiográfico", tal como Escajadillo (1994) lo había descrito —creemos - apresuradamente. Sino, más bien, un vehículo de ideas, el cual continuará por la misma ruta que venían formando sus artículos de opinión en la prensa escrita de aquellos mismos años. Cabe, entonces, que nos preguntemos: ¿qué lineamientos ideológicos se fijan entre las historias de Pobre gente de París? 


\section{Pobre gente de París: retrato de los artistas evasivos}

En este segmento de nuestro trabajo, a partir de la identificación de las ideas base que Salazar Bondy expuso y defendió, entraremos a su libro Pobre gente de París; de ese modo intentaremos reconocer hasta qué punto se hallan relacionadas esas mismas ideas con los temas presentes y la resolución de algunas de las historias que conforman el libro. Para conseguir dicho objetivo nos valdremos de sus artículos periodísticos y sus críticas de arte, pues a través de aquellos textos fue que nuestro autor difundió su visión del mundo. Como el principal asunto que se le cuestionó a Salazar Bondy fue el grado de compromiso de su literatura para con su ideología, creemos conveniente que la selección de los cuentos a ser analizados también tenga como tema central la actitud de los artistas frente a su realidad, por lo que los siguientes cuentos serán los elegidos: "El cisne en el estiércol (Fragmento de una novela inédita de José Olmos Gualfreducci)", "Carta a Panamá”y "Un chaleco color de rosa”.

\section{El papel de los artistas e intelectuales: las ideas base de Salazar Bondy}

Los principales lineamientos del pensamiento de Sebastián Salazar Bondy se encuentran sostenidos en una idea fundamental: la liberación de los oprimidos será posible a través de la difusión de la cultura, la cual permitirá que todos accedan a un estado de paz y progreso social. La solidaridad de los hombres se fortalece con la evolución de su sensibilidad, de su humanidad. El arte es ineludible, por ende. Su pensamiento ético y estético se estructura a partir de tres elementos exactos (los énfasis son nuestros):

\section{La revolución a partir de la cultura:}

En la raíz de este mal está la conspiración oligárquica contra el pueblo trabajador [...] No habrá, así las cosas, reforma total de la educación, por más que los pedagogos conscientes intenten afanosamente romper la estructura en la que se sustenta este plan de dominio de unos cuantos sobre la mayoría. Y, como es lógico, la estructura o superestructura educativa del feudalismo y el capitalismo peruanos reposa en la estructura socioeconómica. Es a ésta a la que hay que atacar rotundamente, sin vacilaciones. La cultura es el petardo que más teme la oligarquía. Su ingrediente es la verdad que, paso a paso, con dificultades y fracasos, ha movido la marcha de las mayorías hacia el 
poder, desde el cual ellas establecen la paz, el bienestar, el progreso general. (Salazar, 2003, p. 80)

2. El compromiso de los intelectuales:

De ahí que rechacemos la idea del intelectual puro, del individuo solitario y satisfecho que se entrega a su obra divorciado de la realidad burda de todos los días. Tenemos que vivir en el barro de la existencia común, metiendo la mano en él sin temor a mezclar nuestros sueños con la sustancia viva y caliente que constituye la vigilia terrestre. (Salazar, 2003, pp. 85-86).

3. La vinculación del arte y la política:

La literatura me ha dado muchas satisfacciones y me las sigue dando. El Perú, América Latina, el mundo hambriento, son para mí, sin embargo, motivos que justifican que continúe en la creación y esté, a la vez, en la trinchera política. Mi conciencia está tranquila. Miro con la frente alta y diviso, en el horizonte, el advenimiento del mundo socialista humanista de paz, bienestar y progreso. (Salazar, 2003, pp. 182).

Como podemos observar, Salazar Bondy establece un plan desarrollado a partir de la igualdad de oportunidades, es decir, la educación no como lujo de una élite determinada, sino con acceso a la mayor cantidad de personas, si no es posible con todas ellas. De igual modo, desde su perspectiva, el hombre de artes y letras debe estar consciente de que su papel no se detiene en la elaboración de una obra para su satisfacción egoísta o exclusivista, y que, más bien, debido a su lugar en la sociedad debe luchar por hacer de ésta un espacio donde las libertades del ser humano no sean derribadas ni disueltas despóticamente. Por supuesto que la identificación de estas tres directrices es artificial, útil para los objetivos de nuestro trabajo. Porque cultura y política no pueden —nunca deben- estar distanciados, ya que entre ambas se hallan los ciudadanos, la sociedad en su conjunto. Salazar Bondy, por esta razón, considera inadmisible la distinción que hacen con su propia persona, entre el escritor y el político, cuando ambos son uno solo, se integran y no se anulan.

Esta postura, por lo tanto, explica la virulencia de las palabras que Salazar Bondy utiliza para referirse a aquellos artistas que eligen partir al extranjero, calificándolos de "Narcisos", ajenos a un sentido social, verdaderos seres mutilados por su irrefrenable egoísmo. Su ataque, por supuesto, es más duro contra quienes cargan con un diploma o un título académico — signos 
indistinguibles de alta cultura - y que se han eximido de toda responsabilidad, de todo interés por la realidad de su país. Estos egoístas serán los culpables de incentivar la desarticulación de las sociedades humanas.

Son los que hablan de la 'lucha por la vida' como asunto personal, los que sostienen la teoría de que ser rico o pobre es cuestión de habilidad y azar, los que creen en la falacia del destino o la fortuna trazado de antemano, quienes pertenecen a ese género de egoístas que levantan, habitan y defienden su torre, de marfil. (Salazar, 2003, p. 187)

Un aspecto interesante es que Salazar Bondy condena no solo su egoísmo, peligroso ya para la comunión de los hombres, sino también su indiferencia política: "Derechista o izquierdista, el ciudadano que no se siente desgarrado por el hambre, el abandono, el despojo y el dolor de las mayorías, es un traidor" (2003, p. 128). No hay que dejar de prestar atención al hecho de que este artículo, que alberga palabras tan apasionadas, siendo una verdadera invectiva, es de 1956.

El contacto con la realidad jamás tendría que deshacerse, según Salazar Bondy, pues contribuye a que el artista mantenga una retroalimentación con su entorno, con su comunidad, pero también a que esta misma comunidad pueda comunicarse a través de las obras de ese artista. El compromiso del arte, entonces, no será con una única forma de mirar el mundo, sino con el propio mundo. En otro artículo, pero de 1957, Salazar Bondy retoma la polémica del abstraccionismo. Como se sabe, en 1954, por medio de una serie de cartas aparecidas en los principales diarios de Lima, nuestro autor entró en un enérgico debate con los representantes de la agrupación Espacio — entre ellos, un viejo amigo suyo, el pintor Fernando de Szyszlo-, quienes propugnaban la importancia del arte no figurativo, ya sea en la pintura, la escultura o la arquitectura. La crónica, que gira en torno a la obra del, en ese entonces, joven pintor francés Bernard Buffet, le permite a Salazar Bondy desacreditar el sentido de la pintura abstracta, pues esta no contribuiría con el desarrollo de cualquier comunidad necesitada de dignidad y libertad, debido a su obscena avidez de 
comercializarse, de ser un espectáculo, antes que una actitud honesta:

Pintor de la depresión de una generación, pintor a gusto de quienes no quieren ni demasiada alegría ni demasiado horror, pintor cuyas enormes facultades ha sido puestas sin pudor al servicio de un mercado, Buffet puede ser una gran estafa, pero indiscutiblemente es un testimonio del estado del espíritu de nuestro tiempo. (1990, p. 209)

La línea que se va forjando entre uno y otro artículo, ejemplos concisos del abundante material preparado por Salazar Bondy cada semana y que luego saldrán en las páginas de los diarios, es la siguiente: la condena de los artistas evasivos ocurre cuando ellos aceptan el triunfo pasajero, el éxito económico, o simplemente la mera satisfacción personal y deciden olvidar al propio país. El desentendimiento de los problemas que requieren urgente solución, entre ellos el cambio de mentalidad y de valores a través de la educación ("el petardo que más teme la oligarquía”), conlleva a que dejen de lado su rol ante el resto de la sociedad. Pero, también, a olvidar sus antecedentes, sus raíces históricas. La memoria que termina siendo un lastre y donde solo les importa la veleidad del presente, de la moda comercial, de la plena imitación de moldes sin contenido. Los artistas evasivos — desde la mirada de Salazar Bondy— son narcisistas y por ende son traidores. No solo con sus sociedades, sino —-más grave aún— consigo mismos.

Siguiendo esa misma dirección, la escritura y posterior publicación de Pobre gente de París no significa un paréntesis o un momento de solaz. Este libro, cada uno de sus cuentos, el tono de su narrador, las aventuras de sus protagonistas, todo, absolutamente todo, persiste en el afán inicial de su autor: la propagación y fortalecimiento de la doctrina socialprogresista, del socialismo humanista. Es parte de la misma marea. No hay interrupciones. La concepción teleológica de la historia que le impone la esperanza en la doctrina lleva a que Salazar Bondy indique, en más de una oportunidad, el advenimiento de una nueva era. Sobre todo, cuando, unos años después, entre 1961 y 1962, se mantuvieran encendidos los fuegos por las elecciones presidenciales y del 
senado (los énfasis son nuestros): "Hay, sin embargo, una ley histórica que se cumple inevitablemente: los pueblos llegan a saber cuál es la verdad y van sin temores a ella" (2003, p. 154); "La lucidez de los intelectuales llevará al mundo a ordenar la economía en el sentido de establecer el bien común [...] así lo quiere la humanidad que marcha hacia un día cuya fecha constituirá un triunfo del hombre y una derrota del egoísmo humano" (Salazar, 1994, p. 182).

\section{Pobre gente de París o los artistas que no quieren conocer a la realidad}

Pobre gente de París (1958) es un conjunto de quince cuentos que se articulan en torno de la figura de su narrador protagonista, el peruano Juan Navas. Ocho capítulos encierran la historia de desamor que sufre el protagonista con una mujer francesa, y siete historias más, intercaladas entre capítulo y capítulo, nos enseñan las desventuras de los emigrados latinoamericanos en París. Los personajes de estos siete cuentos se vinculan - a excepción de dos casos puntuales: una pareja de enamorados músicos, un colombiano y una española, y un par de funcionarios de un organismo internacional, un español y un mexicano- en distintos pasajes de la historia principal con Juan Navas. El tipo de narración es tradicional, no hay experimentación en ninguno de sus aspectos.

El primer cuento que revisaremos es "El cisne en el estiércol". La narración es presentada como el fragmento de una novela inédita de José Olmos, un escritor argentino compañero de Juan Navas. En este cuento somos testigos de las habilidades persuasivas de La Nena, una estudiante venezolana de escultura, que debe seducir al coronel Olórtegui Ramos, ministro de la dictadura en su país, para que le otorgue la beca que le permita cumplir con su más preciado sueño: viajar a París. Para llevarlo a cabo tendrá que sostener relaciones íntimas con el ministro en su propio despacho, aunque para ello deba soportar todo lo desagradable del hecho.

Aparentemente, estamos ante un cuadro con un solo cazador, el coronel Olórtegui, y una sola presa, La Nena. Sin embargo, podemos advertir que el poder se halla en quien sepa controlar el deseo carnal. Por lo que se da una inversión de papeles, con La Nena aprovechando su sensualidad para obligar al 
coronel que le otorgue lo que ella necesita: “[del ministro Olórtegui Ramos] de quien esperaba todas las humillaciones, pero también el dorado galardón del viaje a Europa, de la partida dichosa hacia la aurora del espíritu” (Salazar, 1964b, p. 61). El que La Nena distinga el viaje a Europa como un acceso a un mundo civilizado, donde las actividades del espíritu, como el arte, son valoradas es una clara manera de censurar la realidad de su entorno, de Venezuela y del resto de Latinoamérica10. Por ello, en oposición a Europa, el continente americano es la tierra de la barbarie, el reino de lo material, de lo carnal. Por ello, la estudiante tiene que recurrir a explotar su propio cuerpo, igual que una nación lo haría con sus recursos naturales, para obtener la riqueza deseada:

\footnotetext{
Estaba empeñada en disimular ante sí misma y ante el Ministro Olórtegui Ramos, y ante sus camaradas de Bellas Artes, invisibles pero presentes en esa cita en la que pagaba con una defección ética su victoria vital, su caída en el fondo de la ciénaga. (Bondy, 1964b, p. 62; el énfasis es nuestro)
}

La reacción del ministro es inicialmente de desenfreno, por la ilusoria presa que cree tener entre sus manos; mas cuando la estudiante, de forma muy estratégica, le proponga la posibilidad de quererse quedar con él, aparentemente enamorada, el ministro preferirá deshacerse de ella, aunque ofreciéndole aquello por lo que su joven amante había venido desde un principio: la beca para ir a París: “Todos los jóvenes artistas quieren ir a París. ¿Por qué tu no?" (Salazar, 1964b, p. 62). Los artistas lucen, ante los ojos del militar, como unos parásitos. La actitud de la estudiante es pragmática: no importan los medios, tan solo el objetivo final: "para apoderarse del premio que venía galopando en la caricia del Coronel Olórtegui Ramos” (Salazar, 1964b, p. 62). Su concepción de la vida es la de una eterna competencia, donde si uno no se arriesga, no gana. Lo que deriva inexorablemente en que sea una verdadera cínica, actuando como una pobre víctima de las circunstancias antes los ojos del mundo, pero habiendo calculado fríamente cada mínimo detalle: "simulando gratitud hacia su nuevo amante, aunque estaba tentada de clamar que aquel 
sacrificio era la prueba decisiva de que era capaz de sobrepasar todos los obstáculos que se opusieran a su voluntad de llegar a París" (Salazar, 1964b, p. 64; el énfasis es nuestro). Podemos comprobar que "El cisne en el estiércol" condensa entre sus líneas las vicisitudes que deben soportar los jóvenes artistas cuando se hallan dominados por un entorno que solo es agradable para con los más fuertes. En este caso, la estudiante de bellas artes, proyecto de artista, no lucha contra los mecanismos de dominación que ha impuesto la dictadura militar en su país. Ella prefiere utilizar el método tan fácil como sucio, aunque ello le cueste la degradación de su propio cuerpo. Su elección hace que ella deje de ser una víctima y pase a ser una cómplice de ese mismo perverso sistema. El autoengaño, creyendo que el encuentro con el ministro es solo un pequeño peldaño para llegar a la cima, cuando en realidad está perdiendo todo respeto ante sí misma; se nutre mutuamente con su egoísmo, con su falta de solidaridad para con su sociedad, ofreciendo su cuerpo a uno de los esbirros de la dictadura, con tal de escapar lejos de esa tierra de barbarie en la que se ha convertido su país.

El siguiente cuento que nos interesa utiliza una presentación formal distinta: “Carta a Panamá”. Dicha carta es dirigida desde París por un joven pintor colombiano, Darío Dianderas, a la madre de su colega y compañero, el panameño Harold Estrella. El motivo por el que la redacta es para informarle a la madre del malestar mental que se ha apoderado de su hijo, teniendo que explicar con detalle las circunstancias que lo llevaron a caer en ese estado. Debido, principalmente, a las condiciones miserables en las que tienen que vivir, así como a las expectativas frustradas de ambos por intentar entrar no solo al circuito comercial de la pintura abstracta, de la cual ambos son asiduos practicantes, sino por obtener, también, un reconocimiento oficial de sus talentos.

La carta es una sucesión de relatos que contribuyen a que - los lectores junto con la madre, la destinataria original— nos imaginemos el ambiente en el que se encuentran ambos jóvenes latinoamericanos. Desde la presentación que hace de sí mismo, el colombiano Dianderas demuestra lo arduo que es entrar a ser parte de las camarillas de artistas en París: “También yo soy pintor y estoy en 
Francia desde hace tres años" (Salazar, 1964b, p. 108; el énfasis es nuestro). No solo lo impide la ausencia de relaciones de afinidad, las que dentro del mundo del arte suelen ser bastante necesarias, sino también la estrechez económica en la que se hallan. Debiendo desempeñar labores distantes del gran arte:

Por las mañanas él salía a trabajar de pintor de brocha gorda y yo me quedaba en la casa pintando mis cuadros, y por la tarde cuando yo iba a manejar el ascensor en una estación de ferrocarril, él se dedicaba al arte. (Salazar, 1964b, p. 108)

Durante estos primeros meses de convivencia comparten, pues, los gastos de una habitación para estudiantes extranjeros, logran entonces una especie de armonía. No solo de tiempos y remuneraciones — necesarios para continuar con sus propios trabajos creadores-, sino de deseo y de realidad. Ya que están en pleno París, la ciudad cumbre del arte, desde su perspectiva, y a la vez están pintando, que es para lo que han venido. Es decir, están cumpliendo con la imagen paradigmática del artista romántico: entregados a su arte, aunque ignorados por los circuitos oficiales, teniendo que sobrevivir a duras penas. Sin embargo, esta armonía inicial acabará cuando las resonancias de la realidad, en este caso una huelga general, llegan hasta ellos. Despertándolos del sueño:

Nos podíamos, sin embargo, defender con sacrificios y economías, hasta que vino lo de la huelga. Yo no me metí en nada [...] la policía atacó a los obreros. Nos agarraron a palos y yo caí preso con la frente rota. Felizmente se dieron cuenta de que yo no había hecho nada malo. (Salazar, 1964b, p. 109)

Sucede lo inevitable. Los artistas pueden elegir integrarse con el pueblo en sus reclamos o, simplemente, ignorarlo y continuar con sus acciones. Tanto el colombiano como el panameño se inclinan por querer seguir con su sueño: "Sinceramente le diré que pasamos hambre, pero como sabemos que la vida del artista es dura y que pocas veces la gente lo comprende cuando está vivo, no nos quejamos a nadie" (Salazar, 1964b, p. 110). La distinción que hacen de ellos, frente al hombre vulgar y corriente, se debe a su ciega fe en el ideal de artistas no 
entendidos, congeniando convenientemente con su indiferencia, su inacción política. Esta condición no variará en el resto de la historia, pese a que se ven enfrentados — de una u otra forma — con la realidad. Los premios, entonces, se convierten en la última oportunidad para acceder a los circuitos oficiales. Además de ser la única manera “correcta”, teniendo en cuenta su concepción del artista romántico, en que el dinero puede llegar a sus manos: "hicimos cuadros y cuadros con esperanzas de ganarnos el premio, aunque no ignoramos que hay camarillas y favoritismos, y que nuestra concepción del arte no es aceptada todavía por los burgueses" (Salazar, 1964b, p. 110). Descubrimos que para los dos jóvenes pintores, que comienzan a desengañarse cada vez más, el arte pasa de ser un ideal, sin tiempo y sin espacio, a un mercado con fluctuaciones y modas. Los burgueses, pese a ser una especie distinta a los artistas, como lo eran los hombres comunes, son sus clientes. Por lo tanto, no tienen problemas con ellos más que el de su retrasada sensibilidad. Es este cuento encontraremos claras alusiones a la polémica del abstraccionismo con la que Salazar Bondy tuvo que lidiar. Nos referimos a la mención que se hace de Bernard Buffet, pintor de moda, el máximo representante de la corrupción del arte, ahora devenido en mera mercancía:

Por más que le pregunté a dónde íbamos, no me lo dijo. "Cállate —me decía-, que si se entera Buffet que me han comprado un cuadro va a intrigar". Buffet, señora, es un pintor de moda, un pintor de sociedad que los ricos compran mucho. (Salazar, 1964b, p. 110)

La censura de Salazar Bondy regresa soterrada en la voz de su personaje. Coincidiendo con el pasaje en que el pintor panameño pierde por completo la lucidez, desesperado como está. La serie se cierra cuando se confirma su filiación: "nosotros éramos abstractos" (1964b, p. 112). La enfermedad —pues el panameño comienza a sentir alucinaciones— ayudará a su desenmascaramiento: "Dice también que el gobierno de su país le va a comprar ese cuadro en varios miles de dólares y que le pagarán el pasaje de vuelta a su patria, donde será recibido con todos los honores" (Salazar, 1964b, p. 112). El arte no es una 
necesidad vital para ellos, sino un medio más para escapar de su condición de ciudadanos de clase media. De allí que puedan excluirse tanto de una clase inferior (los obreros) como de una superior (los burgueses). La sofisticación que ven en el arte los hace apartarse de su realidad, en todos los sentidos de la expresión: ya sea viajando a París, ya sea sufriendo de alucinaciones. Otra vez el egoísmo de los artistas los lleva al autoengaño, y este al exilio, al escapismo.

El último cuento, "Un chaleco color de rosa”, fue el único de Salazar Bondy que apareció en una antología mientras estuvo con vida. Fue en la de 1960, preparada por Alberto Escobar. En este caso, la historia es protagonizada por un peruano, el poeta Roque Linares, quien necesita comprar una nueva prenda, el chaleco color de rosa, pues, según piensa él, le será útil en la fiesta a la que ha sido invitado. Asistir a dicha celebración significa bastante para sus aspiraciones de ascenso social. Así, de lograr un buen impacto con su imagen, sabe que se le abrirán las puertas, tanto para él como para su obra, después de tantos intentos. Mas su único inconveniente es que no tiene el dinero a la mano. De modo que cuando llegue a él, de forma totalmente imprevista, la cantidad requerida, no dudará en comprar la ansiada prenda.

El deseo de ascender socialmente de Roque Linares se halla materializado en un solo objeto, la llave de las puertas al éxito: el chaleco que acaba de ver en una tienda de ropa para caballeros en París. Aunque el personaje prefiera, como para sacudirle las máculas que pudiese tener, llamar a ese deseo de una forma distinta:

Roque Linares convenía que la poesía, para él, era algo más que un ejercicio literario [...]. Y si la poesía asumía a veces la forma de los catorce versos de un soneto, nada impediría que adoptara el estupefaciente aspecto de un chaleco color de rosa. (Salazar, 1964b, p. 137)

Desde el primer momento que nos cruzamos con su figura, se puede ver que la necesidad de destacar en la vida es el imperativo de Roque Linares. Y que para conseguirlo tendrá que recurrir a la poesía o a su carisma personal. El arte es 
tan solo un artefacto para escapar del anonimato que se yergue por sobre el resto de la masa. Sacerdote del mercantilismo, el poeta peruano está al tanto de cuáles son los rituales que deberá cumplir para lograr sus objetivos. La creatividad y el talento, al parecer por su poca fortuna en la literatura, terminan desperdiciados con la poesía, son mejor dirigidos por su arribismo impetuoso: “y tener para esa noche una invitación 'chez Madame' Lou Nivroska-Benoit, quien animaba, una tertulia de intelectuales proustianos de alto refinamiento y estricta selección. La prenda rosada del Boulevard Malesherbes había creado un vacío en su vida" (Salazar, 1964b, p. 137). Por ello, este poeta está convertido totalmente en un siervo de su propia ambición. Solo lo domina el afán de figurar, su condición de artista ha sido dejada de lado. De allí que inclusive su identidad la utilice — jugando con ella - para seguir con su plan de ascenso social: "el viso acaramelado de su piel, aquel rasgo racial que solía atribuir, cuando la ocasión era propicia, a sus imaginarios antepasados incas, creadores de un antiquísimo mundo de exquisito salvajismo" (Salazar, 1964b, p. 138). Su historia es otro objeto más, así como una prenda o una joya, que puede servirle para mantener la imagen de artista diferente, sensible. Esto le lleva a inventar su pasado. Cabe decir que no tiene uno real. Es una más de sus artimañas para sobrevivir en las calles de París. Sin identidad, sin historia, es esclavo de su presente, que, como hemos visto, también es una construcción basada en apariencias y engaños. Por supuesto que su preocupación por los otros es totalmente nula. Desarraigado gracias a su ambición, es capaz de cualquier acción con tal de no perder lo que, según él considera, le debe el destino. La aparición casual —un oportuno deus ex machina — del tío de Juan Navas, el joven peruano protagonista principal de Pobre gente de París, nos referimos a Felipe Armijo, guiará a Linares directo a su chaleco color de rosa. Y es que Linares, desesperado de dinero, se acercará al Consulado peruano para averiguar si por un golpe de azar se le ha adelantado el pago que mensualmente recibe gracias a gestiones de su padre en Lima. La respuesta será negativa. Sin embargo, su condición de conocido del cónsul, además de saberse que es practicante de la poesía, le servirá para que reciba una propuesta. El tío de 
Juan, el señor Armijo, necesita enviarle un dinero a su sobrino, pero por lo inminente de su partida necesita que alguien que lo conozca pueda entregarle un dinero en sus propias manos. El cónsul, por este motivo, le preguntará a Linares si estaría dispuesto a ubicar a Juan Navas y de esa manera cumplir con el encargo de su tío. El destino — tal como lo percibe Linares - le está brindando una oportunidad inigualable:

Al recibirlo [el fajo de billetes], Linares tuvo que ocultar un ligero temblor de emoción. Sabía que era aquello lo que inconscientemente había ido a buscar esa mañana al Consulado. El azar concertó la cita, y el azar era —ahora lo percibía muy bien-la expresión de lo que él llamaba voluntad poética. (Salazar, 1964b, p. 139; el énfasis es nuestro)

¿Ante qué tipo de artista nos encontramos en esta última historia? La concepción del arte que maneja es la de una forma de oportunidad más, entre otras tantas, para obtener no solo el éxito monetario sino también conseguirse un buen nombre. La "voluntad poética" es apenas una expresión delicada con la cual intenta cubrir su maledicente astucia. Roque Linares es el paradigma del antiartista, si seguimos lo señalado por Salazar Bondy. No solo ha olvidado por completo cualquier tipo de compromiso por su realidad, por su comunidad, por su historia, es un hombre que se ha entregado sin recelos finalmente a su egoísmo, a su incontenible placer que tiene que ser saciado, cueste lo que cueste. Por lo que no le importará ser un ladrón, no cumplir con la palabra ofrecida y dejarse llevar por su necesidad de destacar en la vida, como arribista que es:

Cuando llegó a la puerta de su anfitriona, había llegado a la conclusión que no existía mejor arte que una vida que fuera, ella misma, un grande e impronunciado poema [...] vivido pero no escrito, comenzaron a realizarse cuando una mañana de abril, seis años antes, ascendiera la escalera del [barco]. (Salazar, 1964b, p. 141)

Cada uno de estos artistas se halla en aquel conjunto de individuos que Salazar Bondy calificó de traidores. Indiferentes a su mundo, han renunciado a sus vínculos con el resto de los hombres, para continuar — aparentemente libres, 
pero todo lo contrario- con su sueño, con la realización de sus deseos: París. Sin importarles que en el camino a ese falso paraíso deban degradar no solo sus cuerpos o sus espíritus, sino también sus propias identidades, quedando desarraigados en el mundo, mendigos por elección propia. Es posible reconocer gracias a estas tres historias tres niveles, cada uno más decadente que el otro, donde los protagonistas deben desenvolverse a costa de un falsamente justo sacrificio. De modo que cada uno de ellos ha elegido ser víctima de sus propios deseos. La Nena, accediendo a tener relaciones sexuales con un ministro, nos presenta el primer nivel: antes del viaje, con la angustia en el cuerpo por escapar del país de origen. Harold y Darío, los jóvenes pintores abstractos, dentro del segundo nivel, son claro reflejo de los miles de inmigrantes que habiendo llegado a París, el primer gran objetivo: escapar del país, fracasan irremediablemente. Solo Roque Linares, el hábil poeta peruano, desde el tercer nivel, una vez adaptado a los vaivenes de la vida en París, sabe a través de qué medios, utilizando qué artimañas, logrará el segundo gran objetivo: integrar los círculos de poder que dominan la cultura en París, y por ende, el resto de Europa: "la aurora del espíritu". El autor, como si se tratara de un gran dios que decide el futuro de sus criaturas, ha dictaminado cuáles serán las consecuencias a pagar de cada uno de sus personajes por haber preferido colmar su egoísmo, su vanidad y su orgullo, antes que cumplir con su verdadera parte, como artistas que son, la de demostrar que los hombres — todos- pueden evolucionar a través del arte y de la cultura. Entonces, logramos observar que las ideas de Salazar Bondy discurren sin dificultad entre las líneas de Pobre gente de París. La condena dictada en la página de algún periódico aparece nuevamente en las páginas de este libro, quizá con otras palabras, quizá con diferente extensión, pero siempre con la misma indignación, con la misma ira.

\section{Notas}

'Salazar Bondy se encargó de redactar la presentación general de la selección; asimismo, los textos introductorios a los poemas de Enrique Peña y Carlos Oquendo de Amat.

${ }^{2}$ Recordemos que Sebastián Salazar Bondy, junto a su hermano Augusto, entre otros 
intelectuales de la época, se agruparon para dar vida al Movimiento Social Progresista, que tuvo una muy breve existencia. Sebastián tuvo la oportunidad de postular al Senado por Lima, a inicios de la década de 1960, aunque sin conseguirlo.

${ }^{3}$ Una lograda semblanza para conocer este otro ángulo de Sebastián Salazar Bondy nos da el libro de Juan Gargurevich titulado Historias de periodistas (2009).

${ }^{4}$ Fue director de la célebre revista Las Moradas, donde diversos integrantes de la que luego sería denominada como la "Generación del 50", participarían activamente. Salazar Bondy sería parte del comité de redacción.

${ }^{5}$ Obtuvo el Premio Nacional de Teatro en dos oportunidad: en 1947 por Amor, gran laberinto, y en 1951 por Rodin.

${ }^{6}$ Hay que tener presente que de la misma época es otro de sus ensayos más logrados: "La literatura es fuego" (1966). Éste dedicado a la figura del poeta vanguardista Carlos Oquendo de Amat y el valor de la literatura en la sociedad moderna.

${ }^{7}$ De allí que en el prólogo de esta edición inclusive se nos advierta: "Sobre las opiniones seguramente algo duras que se hallarán sobre algunos contemporáneos de los autores de las cartas, téngase presente que muchas de tales opiniones fueron cambiando con el devenir de los años (destacamos, como ejemplo, el buen entendimiento de ambos escritores con Sebastián Salazar Bondy)" (Westphalen Ortiz, 2011, p. 38; el énfasis es nuestro).

${ }^{8}$ Así sentencia Mario Vargas Llosa el sentido de la época: "Muchos, y sobre todo jóvenes, pero también muchos intelectuales adultos, no admitían la reforma porque querían la revolución. [...] Y la cultura les parecía uno de los instrumentos básicos de la transformación social. [...] [se] Defendía la idea de que la literatura no era gratuita, no era un entretenimiento, que cuando uno escribía novelas o poemas no estaba simplemente creando unas formas estéticas para la exaltación o el placer hedonista de los lectores. No, uno está librando a cabo una batalla contra la confusión, contra el oscurantismo ideológico, estaba esclareciendo una verdades y por lo tanto combatiendo unas injusticias e influyendo sobre la historia. [...] Hoy en día, con pocas excepciones, el intelectual es mucho más modesto en sus ambiciones. Y mucho más irónico, y hasta cínico, respecto a los poderes de la literatura, en particular, y de la cultura, en general, para producir grandes cambios sociales" (Pinilla, 2003, p. 73).

${ }^{9}$ Para nuestro análisis utilizaremos una edición que contiene una breve selección de cuentos de Náufragos y sobrevivientes, el cuento inédito "Dios en el cafetín" y el íntegro de Pobre gente de París. La edición fue preparada el mismo año del fallecimiento del autor, resultando ser asíla definitiva.

${ }^{10}$ ¿Pero de qué modo es que se extiende un aspecto nacional a uno más grande, a uno regional? Ocurre que Salazar Bondy era un defensor del americanismo. Es decir, proponía una autonomía de los latinoamericanos — en lo que a cultura y pensamiento se referíande los europeos o de los norteamericanos. Así pues, él creía en la unidad de las naciones latinoamericanas. Cuestión que nos ayuda a entender por qué se utilizan personajes de distintas nacionalidades en Pobre gente de París. Reflexionar sobre el compromiso de los artistas no lo circunscribía a nuestro país solamente, sino a toda América Latina.

\section{Referencias bibliográficas}




\section{Bibliografia primaria}

Salazar Bondy, S. (1954). Náufragos y sobrevivientes. Lima, Perú: Club del Libro Peruano.

Salazar Bondy, S. (1958). Pobre gente de París. Lima, Perú: Juan Mejía Baca.

Salazar Bondy, S. (1963). Mil años de poesía peruana. Lima, Perú: Populibros peruanos, 1963.

Salazar Bondy, S. (1964a). Lima la horrible. Ciudad de México, México: Era.

Salazar Bondy, S. (1964b). Dios en el cafetín. Lima, Perú: Populibros peruanos.

Salazar Bondy, S. (1969). Alférez Arce, teniente Arce, capitán Arce. Lima, Perú: Casa de la Cultura del Perú.

Salazar Bondy, S. (1990). Una voz libre en el caos: ensayo y crítica de arte. Lima, Perú: Consejo Nacional de Ciencia y Tecnología.

Salazar Bondy, S. (2003). Escritos políticos y morales (1954-1965). Lima, Perú: Fondo Editorial de la Universidad Nacional Mayor de San Marcos.

\section{Bibliografía secundaria}

Cornejo Polar, A. (1982). Sobre literatura y crítica latinoamericanas. Caracas, Venezuela: Universidad Central de Venezuela.

Cornejo Polar, A. (2013 [1979]). "Hipótesis sobre la narrativa peruana última”. En Sobre literatura y crítica latinoamericanas. Obras Completas, volumen 6 (pp. 151-167). Lima, Perú: Centro de Estudios Literarios Antonio Cornejo Polar.

Eielson, J. E., Salazar Bondy, S. y Sologuren, J. (1946). La poesía contemporánea del Perú. Lima, Perú: Cultura Antártica.

Escajadillo, T. (1994). Narradores peruanos del siglo XX. Lima, Perú: Editorial Lumen.

Escobar, A. (1960). La narración en el Perú: estudio preliminar y notas. Lima, Perú: Juan Mejía Baca.

Gargurevich,J. (2009). Historias de periodistas. Lima, Perú: Ediciones La Voz.

Gutiérrez, M. (2008 [1988]). Generación del 50: un mundo dividido. Lima, Perú: Arteidea.

Heysen Pacheco, P. Anexo 2. Entrevista a Santiago Agurto Calvo. Logo/topo. Materiales de Investigación, 2(3), p. 201.

Hirschhorn, G. (2015). Sebastián Salazar Bondy: Pasión por la cultura. Lima, Perú: Fondo Editorial de la Universidad Nacional Mayor de San Marcos, Instituto Francés de Estudios Andinos.

Pinilla, C. (Ed.). (2003). Primera mesa redonda sobre literatura peruana y sociología del 26 de mayo de 1965. Lima: Instituto de Estudios Peruanos.

Rebaza Soraluz, L. (2000). La construcción de un artista peruano contemporáneo: poética e identidad nacional en la obra de José María Arguedas, Emilio Adolfo Westphalen, Javier 
Sologuren, Jorge Eduardo Eielson, Sebastián Salazar Bondy, Fernando de Szyszlo y Blanca Varela. Lima, Perú: Fondo Editorial de la Pontificia Universidad Católica del Perú.

Romualdo, A. y Salazar Bondy, S. (1957). Antología general de la poesía peruana. Lima, Perú: Librería Internacional del Perú.

Sologuren, J. (1988). Gravitaciones \& tangencias. Lima, Perú: Colmillo Blanco.

Westphalen, E. A. (2004). Poesía completa y ensayos escogidos, edición, prólogo y cronología de Marco Martos. Lima, Perú: Fondo Editorial de la Pontificia Universidad Católica del Perú.

Westphalen Ortiz, I. (2011). (Comp.). El río y el mar: Correspondencia José María Arguedas / Emilio Adolfo Westphalen (1939-1969). Lima, Perú: Fondo de Cultura Económica.

Vargas Llosa, M. (1966). La literatura es fuego. Revista Peruana de Cultura, 7-8, 21-54.

Vargas Llosa, M. (2003 [1966]). Sebastián Salazar Bondy y la vocación de escritor en el Perú (pp. 13-35). En S. Salazar Bondy, Escritos políticos y morales (1954-1965). Lima, Perú: Fondo Editorial de la Universidad Nacional Mayor de San Marcos. 